\section{Lazarus-Phänomen: Comeback nach dem Ende}

\author{
Über den Fall einer Patientin, deren Kreislauf nach Aufgabe der Reanimations- \\ bemühungen von selbst wieder angesprungen war, wurde von der University \\ of Illinois berichtet.
}

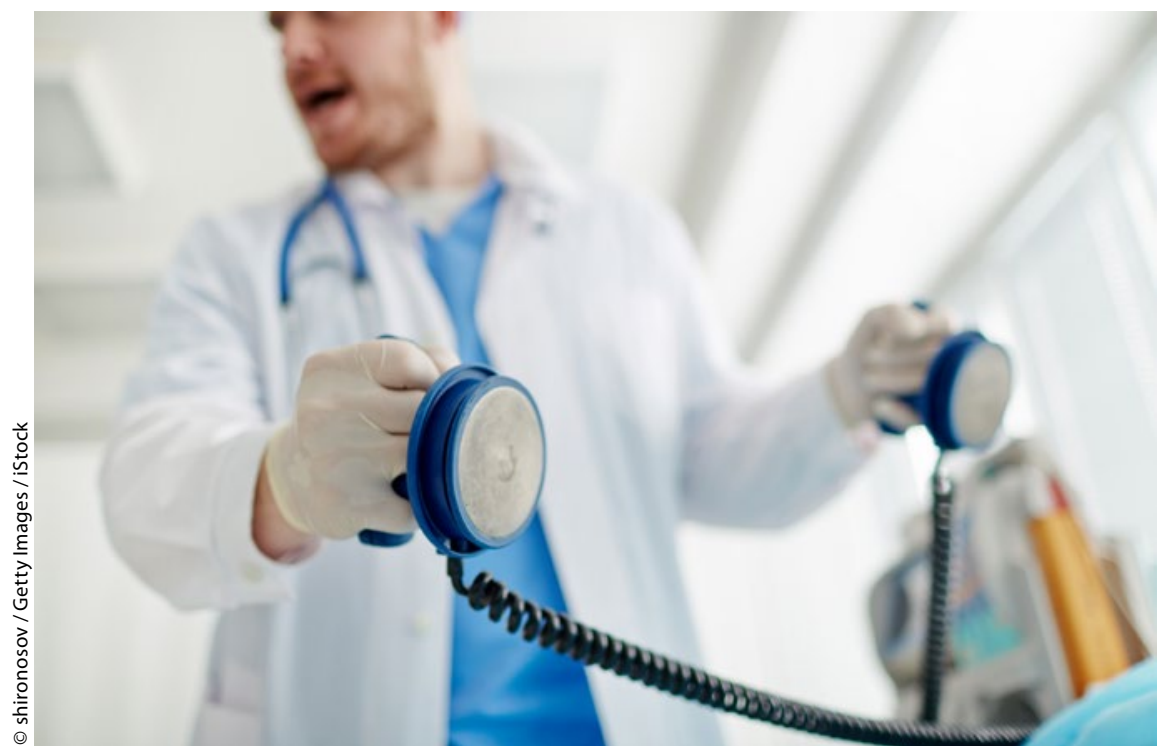

$\mathrm{D}$ ie Patientin ist 69 Jahre alt und nach einer Fraktur des Dens axis quadriplegisch. Sie leidet an einer Niereninsuffizienz im Endstadium und ist dialysepflichtig. Wiederholt hat sie Harnwegsinfekte gehabt. Als sie jetzt in die Klinik eingeliefert wird, hat sie $39,3^{\circ} \mathrm{C}$ Fieber. Unter dem Verdacht einer Sepsis, bedingt durch einen Harnwegsinfekt und eine infizierte, sakral gelegene Wunde, behandeln die Ärzte der Universitätsklinik von Peoria, Illinois, die Patientin mit Breitspektrum-Antibiotika. Die Kaliumkonzentration beträgt 6 $\mathrm{mmol} / \mathrm{l}$. Man bringt die Patientin zur Hämodialyse.

Eine Viertelstunde nach Beginn der Blutwäsche wird die Patientin zunächst bradykard, dann pulslos. Binnen $30 \mathrm{Se}-$ kunden trifft das Reanimationsteam ein und stellt eine elektromechanische Entkoppelung fest. Die kardiopulmonale Reanimation beginnt, die Patientin erhält Epinephrin, Kalzium und Bikarbonat. Der Rhythmus ändert sich in Kammerflimmern, worauf multiple Defibrillationsversuche erfolgen. Zusätzlich erhält die Frau Amiodaron. Nach 25 Minuten vergeblicher Bemühungen, die die trauernde Familie versammelt sich um das Bett.

Zehn Minuten später wird das Team zurückgerufen. Die für tot erklärte Patientin zeigt ein agonales Atmungsmuster und hat starke Karotispulse. Sie wird sofort auf die Intensivstation verlegt. Zwar lebt sie auch noch bei ihrer Entlassung aus der Klinik; sie verfügt aber nur noch über einen minimalen Bewusstseinszustand.

Nach der im Johannes-Evangelium beschriebenen Wiedererweckung des Lazarus durch Jesus vier Tage nach seinem Tod werden Fälle wie der oben beschriebene als Lazarus-Phänomen bezeichnet: als Rückkehr einer spontanen Kreislauffunktion nach Abbruch von Wiederbelebungsmaßnahmen bei reanimationspflichtigen Patienten. Für das Phänomen existieren verschiedene Erklärungsmodelle, sie reichen von der Entwicklung eines Auto-PEEP mit Verminderung des venösen Rückflusses während der Reanimation über eine Hyperventilation mit Alkalose und verzögerter Medikamentenwirkung bis $\mathrm{zu}$ Elektrolytverschiebungen und verspäteter Katecholaminwirkung bei eingeschränktem koronarem Blutfluss. Empfohlen wird, Patienten nach der Beendigung von erfolglosen Reanimationsmaßnahmen noch 10-15 Minuten per Monitor zu überwachen, wenn keine sicheren Todeszeichen vorliegen.

(rb)

Meeker JW et al. A Case Report of Delayed Return of Spontaneous Circulation: Lazarus Phenomenon. Am J Med 2016, online 1. August; doi: 10.1016/j.amjmed.2016.07.009

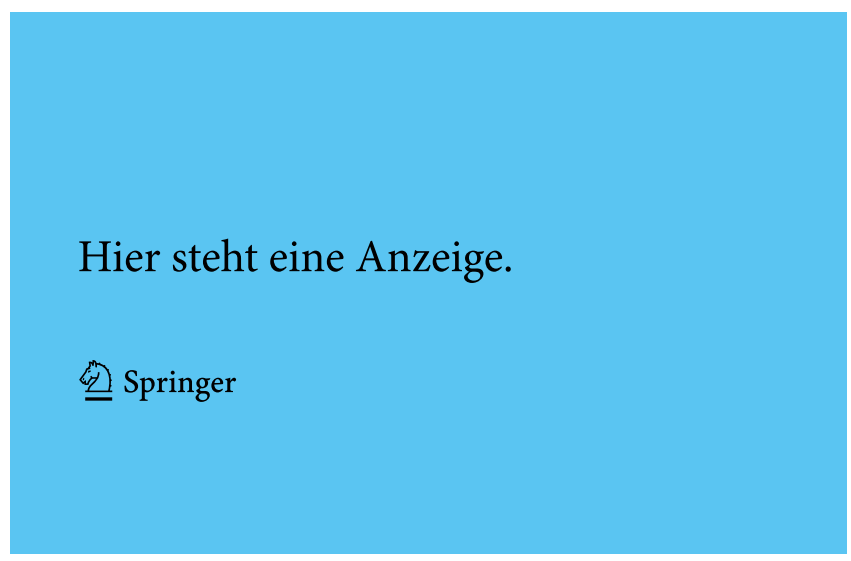

